\title{
REFLEXÕES SOBRE MÚSICA, TELEVISÃO E EDUCAÇÃ̃
}

\author{
Eliane Hilario da Silva Martinoff ${ }^{1}$ \\ Sarita Raquel Belo Ferreira ${ }^{2}$
}

\begin{abstract}
Resumo: Observa-se que atualmente a televisão está presente nos hábitos cotidianos de crianças e jovens, exercendo um papel formador- em termos de atitudes, vestimentas, vocabulário, repertório musical, entre outros aspectos -, sobre o qual a escola deve refletir. Esse estudo de natureza bibliográfica, tendo como aporte teórico Gardner (1999) e Magalhães $(2003,2007)$ objetiva refletir a respeito da influência dos programas televisivos infantis sobre as crianças nas décadas de 1960, 1970 e 1980, no que tange à cultura musical e o ensino de música na escola pública brasileira nesse período e suas possíveis consequências para os dias atuais. Concluiu-se que é importante saber utilizar o que a criança traz consigo em termos de repertório musical, pois a fruição da música está sujeita a diferentes mediações e a escola pode vir a ser o lugar de construção de um conhecimento significativo e reflexivo sobre a música presente no cotidiano.

Palavras chave: Televisão e educação; Ensino de música; Cotidiano escolar.
\end{abstract}

\section{REFLECTIONS ON MUSIC, TELEVISION AND EDUCATION}

\begin{abstract}
It is observed that currently the television is present in the everyday habits of children and youth, exerting a trainer role - in terms of attitudes, clothing, vocabulary, music repertoire, among other aspects-, on which the school must reflect. This study of bibliographical nature, having as theoretical contribution Gardner (1999) and Magalhães (2003, 2007), aims to reflect about the influence of television programs for children about children in the 1960, 1970 and 1980, in terms of musical culture and music education in Brazilian Public schools during this period and the possible consequences for the present days. It was concluded that it is important to use what the child brings in terms of musical repertoire, because the enjoyment of music is subject to different mediations and the school can be the place to build a significant and reflective knowledge about the music present in daily life.
\end{abstract}

Keywords: Television and education; music education; daily life at school.

\footnotetext{
${ }^{1}$ Professora do curso de Pedagogia da Universidade Municipal de São Caetano do Sul, nas disciplinas Metodologia e Prática do Ensino de Arte e Brinquedos e Brincadeiras na Educação Infantil. Doutora e Mestre em Música pela UNESP (Universidade Estadual Paulista Júlio de Mesquita Filho).

${ }^{2}$ Grupo Fênix de Educação - professora auxiliar. Estudante de pós-graduação na Universidade Municipal de São Caetano do Sul (USCS)
} 


\section{Introdução}

No âmbito acadêmico observa-se atualmente um interesse crescente pelas questões culturais, pois a cultura perpassa tudo o que acontece em nossas vidas e todas as representações que fazemos desses acontecimentos. Na educação e nas ciências sociais, a cultura é mais do que um conceito acadêmico, pois diz respeito "às vivências concretas dos sujeitos, à variabilidade de formas de conceber o mundo, às particularidades e semelhanças construídas pelos humanos ao longo do processo histórico e social" (GOMES, 2003, p. 75).

Dentre os pesquisadores das questões culturais - entre os quais saliento o historiador francês Dominique Julia (2001), Antonio Viñao Frago (1995) ${ }^{3}$ e o linguista francês André Chervel (1990)-, nota-se também a importância dada aos estudos referentes à cultura escolar; esses pesquisadores entendem que a cultura escolar referese à maneira pela qual as pessoas envolvidas diretamente com o processo educativo alunos, professores, diretores, pais - compreendem os valores produzidos, transmitidos e aprendidos na escola.

Ainda segundo esses pesquisadores, se considerarmos a educação como um processo contínuo que acompanha, assiste e marca o desenvolvimento do indivíduo, e que envolve a preservação e a transmissão da herança cultural, rapidamente poderemos perceber a importância que o sistema educativo, em geral, e a escola, em particular, assumem na socialização e na perpetuação da cultura, desde a mais tenra idade.

Até o início da década de 1960, os estudos realizados sobre a História da Educação e sobre a infância não pareciam apresentar relações estreitas (ARRIÈS, 1973). Mais recentemente, alguns autores como Shirley R. Steinberg e Joe L. Kincheloe $(2001)^{4}$, e Maria Isabel Bujes (2009) $)^{5}$, entre outros, têm realizado estudos culturais sobre as diferentes formas de se ver e conceber a infância. Como consequência dessas pesquisas, sabe-se que para conhecer as características comportamentais das crianças e adolescentes de um período histórico é preciso lembrar que a infância "é uma construção cultural, social e histórica, sujeita a mudanças" (MOMO e COSTA, 2010, p. 967).

As pesquisas sobre a história da infância - que começaram a surgir a partir do século XIX- são ainda escassas, especialmente no Brasil. Até então, “a vida era

\footnotetext{
${ }^{3}$ Professor de Teoria e História da Educação na Universidade de Murcia, na Espanha.

4 Professores da Universidade de Calgary, no Canadá.

${ }^{5}$ Docente do Programa de Pós-graduação em Educação da Universidade Luterana do Brasil.
} 
relativamente igual para todas as idades, ou seja, não havia muitos estágios e os que existiam não eram tão claramente demarcados" (NASCIMENTO; BRANCHER; OLIVEIRA, 2008, p. 50).

Num estudo sobre as orientações familiares dispensadas às crianças no século XX, Zélia Maria Biasoli-Alves ${ }^{6}$ (1997) comenta que, nas primeiras décadas desse século, observavam-se "o cultivo de valores morais, a exigência de cumprimento das normas, uma educação voltada para o trabalho, fundamentada no 'bom exemplo' das gerações mais velhas". Nas décadas de 1930 e 1940, a educação visava formar um adulto bem educado e, por isso, a ênfase recaía no controle do comportamento, enquanto que nas décadas de 1950 e 1960 o estímulo ao desenvolvimento se dava pela “dispensação da ternura e do lazer para uma vida saudável em família". Nos anos 1970/80 enfatizava-se “o diálogo com a criança, a exigência de compreensão, de afeição, chegando-se ao extremo da preocupação com o seu bem-estar subjetivo" (BIASOLI-ALVES, 1997, p.40, 43).

Sabe-se que, na década de 1950, o rádio era considerado um dos meios mais importantes de lazer e entretenimento em família. Nessa mesma década, foi criado o primeiro programa de televisão, que representou uma revolução cultural e foi paulatinamente conquistando um público cada vez maior. Segundo Alexandre Bergamo $^{7}$, aos poucos, "ganha contornos mais claros a ideia de que a televisão tem um 'público' diferente daquele do rádio, do teatro ou do cinema" (BERGAMO, 2010, p.59).

Alguns trabalhos sobre televisão e educação, como FISCHER (2013), COGO e GOMES (2001), PILLAR (2001), entre outros, partem do pressuposto de que, na atualidade, a televisão está presente nos hábitos cotidianos de crianças e jovens, exercendo um papel formador - em termos de atitudes, vestimentas, vocabulário, repertório musical, entre outros aspectos -, sobre o qual a escola deve refletir, já que é quase impossível ficar indiferente às manifestações culturais divulgadas pela televisão, rádio, cinema, etc.

Segundo um estudo realizado pela Empresa Brasil de Comunicação (EBC) ${ }^{8}$ em 15 regiões metropolitanas do país com crianças e adolescentes entre 4 e 17 anos

\footnotetext{
${ }^{6}$ Professora da Faculdade de Filosofia, Ciências e Letras da USP em Ribeirão Preto.

7 Pesquisador da Faculdade de Filosofia e Ciências da Unesp, campus de Marília.

8 A Empresa Brasil de Comunicação (EBC) é uma empresa pública, que possui um conglomerado de mídia no Brasil (TV Brasil, TV Brasil Internacional, Agência Brasil, Radioagência Nacional e do sistema público de Rádio, composto por oito emissoras: Rádio Nacional AM do Rio de Janeiro, Rádio Nacional AM de Brasília, Nacional FM de Brasília, Rádio MEC AM do Rio de Janeiro, MEC FM do Rio de
} 
pertencentes a todas as classes sociais, em 2004 o tempo médio de exposição à TV (canais abertos e fechados) era de $4 \mathrm{~h} 43$ e, ao longo dos anos, esse período foi aumentando, chegando em 2014 a 5h35 - mais tempo do que uma criança passa na escola diariamente. Os dados coletados no primeiro semestre de 2015 já indicavam 5 h35 de consumo diário de televisão até o final do mês de maio, o mesmo tempo obtido em todo o ano de $2014^{9}$ (TEMPO DE CRIANÇAS, 2015).

Sabe-se, entretanto, que atualmente as crianças também se utilizam de videogames e aplicativos da internet e muitas delas já não querem mais realizar brincadeiras ao ar livre ou gastar tempo com jogos de tabuleiro.

Esse estudo objetiva refletir a respeito da influência dos programas televisivos infantis sobre as crianças nas décadas de 1960, 1970 e 1980, no que tange à cultura musical e o ensino de música na escola pública brasileira nesse período e suas possíveis consequências para os dias atuais.

\section{A televisão e o público infantil}

A partir da década de 1960, a televisão - que iniciara suas atividades na década anterior exibindo filmes, telejornais e alguns programas noturnos direcionados ao público adulto-, passou a exibir desenhos animados em horário diurno, voltados ao público infantil. É importante observar que em 1960, menos de 5\% das residências possuíam um televisor; na década seguinte, esse percentual subiu para $24 \%$, principalmente nas regiões Sul e Sudeste e, nessa região, $40 \%$ dos domicílios possuíam um aparelho de televisão (HAMBURGUER, 2000, p. 448-449).

Aos poucos foram surgindo programas classificados como educativos. Segundo Cláudio Márcio Magalhães ${ }^{10}$ (2007), pode ser considerado como programa educativo aquele que é capaz de

divertir, interagir com o telespectador em geral (e com a criança em particular) de uma maneira mais complexa, prazerosa, despertando-lhe os sentidos em conjunto com a reflexão, agregando informações ao seu cotidiano, reforçando conhecimentos apreendidos na educação formal, produzindo experiências interdisciplinares e extemporâneas (MAGALHÃES, 2007, p. 33).

Janeiro, Rádio Nacional da Amazônia OC, Rádio Nacional AM e FM do Alto Solimões). Foi criada em 2007 para gerir as emissoras de rádio e televisão públicas federais.

${ }^{9}$ Esses dados foram obtidos por meio de um people meter - dispositivo desenvolvido pela empresa Audits of Great Britain-, que permite medir passivamente a audiência das emissoras de TV ou de Rádio.

${ }^{10}$ Professor e pesquisador em Comunicação e Educação, Centro Universitário UNA, MG. 
Ainda segundo esse pesquisador, os programas educativos não são necessariamente apenas aqueles transmitidos por uma emissora estatal ou privada, ou que não tenham qualquer vínculo com o mercado de consumo, obrigatoriamente diferentes dos programas de auditório-apresentador, ou ainda aqueles assim autointitulados como, por exemplo, Globo Ciência, Telecurso 2000, entre outros.

$\mathrm{Na}$ história da televisão brasileira alguns programas para o público infantil marcaram época, como Vila Sésamo na década de 1970, Bambalalão nos anos 1980, Sítio do Pica-Pau amarelo, Cocoricó e Castelo Rá-Tim-Bum, um pouco mais adiante. Nesses programas, muitas vezes as produções eram idealizadas especialmente para transmitir conteúdos pedagógicos ou incentivavam a criação de hábitos comportamentais. Segundo Beth Carmona - diretora de televisão da TV Cultura nesse período -, essa experiência

\begin{abstract}
mostrou a importância da criação de histórias e personagens autênticos, criações que facilmente incorporem traços da cultura local. A série chamada Rá-Tim-Bum foi um fator importante na história de sucessos do canal. Como um empreendimento conjunto entre a televisão estatal e o Serviço Social da Indústria, num esforço de produção de todas as partes, com uma grande equipe de profissionais, duas séries visaram ao público pré-escolar: Rá-TimBum e Castelo Rá-Tim-Bum. Durante o intervalo de produção dessas duas séries, outros programas foram criados, como Mundo da Lua e X-Tudo, para crianças entre 7 e 12 anos (CARMONA, 1999, p.334).
\end{abstract}

Outro modelo de programa direcionado ao público infantil era aquele onde uma apresentadora no estúdio, entre um desenho animado e outro, fazia algumas atividades, como ler cartinhas ou propor jogos interativos; eram assim os programas Pim-Pam-Pum na década de 1960, Zás Trás e a sessão Zig-Zag e seus seguidores nos anos 1970. Muitas vezes a própria apresentadora apresentava como recomendáveis os produtos que patrocinavam aquela programação.

Em 1966, a Rede Globo passou a ser comandada por Walter Clark, e não mais por pessoas do meio artístico. Clark baseou seu trabalho na indústria da propaganda e a consequência foi que a televisão passou a ser "[...] pensada prioritariamente como um empreendimento comercial, e só em consequência disso como um veículo divulgador de arte, cultura, entretenimento, informação. A programação passou a ser pensada em função das estratégias de comercialização da televisão" (KEHL, 1980, p. 174). 
Assim, como observa Sérgio Mattos ${ }^{11}$, “desde o seu início, a televisão brasileira se caracterizou como veículo publicitário, seguindo o modelo comercial norteamericano" (MATTOS, 2002, p. 70).

Segundo a educadora e produtora de materiais didáticos de História, Anna Cristina Camargo Moraes Figueiredo (1998, p. 157), esses anúncios publicitários divulgados na televisão e em outras mídias, como jornais e revistas, incentivavam desde a década de 1950 o consumo como necessidade afetiva, isto é, passavam a ideia de que era necessário consumir.

Beth Carmona reforça essa colocação, quando afirma que "as crianças brasileiras sempre foram vistas como consumidores pela televisão e, sendo assim, os programas produzidos para elas estavam invariavelmente mais preocupados com os interesses comerciais do que com os aspectos sociais ou educacionais" (CARMONA, 1999, p.331).

Houve também na história da TV brasileira alguns ícones, isto é, pessoas que se tornaram grandes referências, verdadeiros ídolos das crianças, como Xuxa e Angélica, entre outras, sempre cercadas por crianças, "anunciando as atrações de uma forma infantil, assim criando um falso senso de proximidade com os espectadores" (CARMONA, 1999, p.331). Para essa pesquisadora,

\begin{abstract}
A apresentadora de programas infantis de maior sucesso no Brasil, Xuxa Meneghel, ou simplesmente Xuxa, criou um formato na TV que se espalhou por toda a América Latina. Originalmente, ela era uma bela modelo e estrela da TV loira, dançando, cantando e brincando com crianças no palco. Durante os programas, ela costumava passar alguns desenhos animados, comerciais, mas, principalmente, anunciava diferentes produtos de consumo, como brinquedos, roupas, iogurte, doces, música e cosméticos. O Хoи da Хиха foi imitado por outros canais, que se utilizavam de garotas loiras, tentando copiar a Xuxa. Tais programas estão no ar há dez anos. Podemos ver Xuxa como um fenômeno comercial deste período (CARMONA, 1999, p. 335).
\end{abstract}

Biasoli-Alves (1997) comenta que, à medida que o século XX foi transcorrendo, "desaparece a rua como ponto de encontro e brincadeiras: a conotação dada ao ambiente doméstico sofre, ao mesmo tempo, alteração de significado, em relação especialmente ao seu uso pela criança" (BIASOLI-ALVES, 1997, p. 41). Dessa forma, enquanto os espaços físicos para as crianças brincarem foram ficando cada vez mais restritos, a procura de diversão e entretenimento passou a ser feita dentro de casa. Daí o sucesso primeiro do rádio e depois com acréscimo da televisão.

11 Professor associado do curso de Jornalismo da Universidade Federal do Recôncavo da Bahia e exprofessor do Programa de Pós-graduação em Comunicação das Faculdades Integradas Ipitinga (Unibahia). 
Assim, destinando diariamente quase seis horas consecutivas de programação para o público infantil e adolescente, a televisão conquistou essa audiência, trazendo não somente diversão e entretenimento, mas influência em seus gostos e preferências, atingindo também os pais, por meio de material jornalístico ou de documentários especialmente selecionados.

\section{Características de alguns programas televisivos infantis desse período}

As séries nacionais com núcleos dramáticos, intitulados programas educativos, como Vila Sésamo, Castelo Rá-Tim-Bum e Cocoricó seguiam a vertente de projetos infanto-juvenis para televisão, apresentando quadros com conceitos pedagógicos, onde conviviam harmoniosamente pessoas de carne e osso com bonecos falantes e seres fantásticos, em um grande Castelo Mágico.

Programas como Castelo Rá-Tim-Bum, Cocoricó, Bambalalão tinham suas trilhas sonoras específicas e muitas das produções que acompanhavam a programação foram compostas especialmente para transmitir conteúdos educativos e, em alguns casos, utilizavam a música como tema principal de vários episódios, trabalhando tipos de instrumentos, ou o próprio conhecimento sobre eles, ritmos e gêneros musicais, entre outros; estes programas também trabalhavam a formação de hábitos como escovar os dentes, tomar banho, o lixo que deve ser jogado no lixo, com canções que ajudavam as crianças a aprenderem naturalmente, com a visível intenção de fixar conceitos, devido à sua reincidência.

Seguindo para o modelo de programa Apresentadora - Auditório, encontramos uma apresentadora no estúdio que, entre um desenho e outro, fazia algumas atividades como, ler cartinhas, joguinhos entre outras. Eram assim os programas Pim Pam Pum na década de 60, o qual era patrocinado pela empresa de brinquedos Estrela; Zaz - Trás nos anos 70, também programa de auditório com uma apresentadora, Márcia Cardeal mais conhecida como Tia Márcia - e a sessão Zig-Zag e seus seguidores. TV Xuxa e Angel Mix foram a quarta geração deste tipo de programa, onde havia quadros musicais, porém apresentando canções que falavam de amor, romance e aventuras amorosas, o que certamente requer mais maturidade da criança, não sendo compatível com sua idade e experiências cotidianas.

Estes tipos de programas apresentavam música popular contemporânea, sempre com alegria e descontração. Ainda nesta configuração, sua programação era variada, 
com informações resumidas, músicas, desenhos e gincanas, visando o entretenimento e a diversão. Assim, olhando de forma analítica, os dois modelos podem ser considerados programas de entretenimento e formação de público para a emissora.

Segundo Magalhães (2007) estas primeiras configurações de programas enxergavam seus minitelespectadores como a Escola Nova; já os programas de modelo apresentador-auditório, como TV Xuxa e Angel Mix viam seus minitelespectadores como a Escola tradicional: no palco uma apresentadora cantando músicas, muitas vezes de sua autoria, e o público, constituído por crianças de idades diversas. Entre blocos de desenho aconteciam gincanas.

No estudo sobre as relações entre televisão e educação, há autores que defendem a ideia de que a TV exerce uma influência nociva sobre as crianças, inibindo sua criatividade e capacidade de reflexão; dentre esses, podemos citar Vasconcelos (1998) e Teixeira (s.d).

Nessa linha de pensamento, observa-se preocupação e crítica ao fato da criança estar exposta por muito tempo aos veículos de comunicação, sob a alegação de que esta exposição excessiva faz a criança se despir do papel de sujeito e vivenciar o papel de objeto em relação à televisão e outras mídias, deixando de realizar suas atividades primárias, que são o brincar e o movimentar-se livremente.

Outra crítica apresentada é o fato de a televisão ter conteúdos multifacetados que podem impedir a criança de se relacionar consigo mesma - habilidade fundamental para seu desenvolvimento cognitivo-, principalmente nos primeiros anos de vida. E por fim, outra questão preocupante é a quantidade de publicidade que estas mídias trazem em seus conteúdos programáticos, principalmente aquela dirigida ao público infantil, pois estas propagandas contribuem grandemente para o consumo excessivo de certos produtos alimentícios, podendo levar à obesidade e à erotização precoce.

Em contrapartida, há autores que acreditam no potencial educativo das mídias, especialmente da televisão. Dentre eles podemos citar Pacheco (1998), Penteado (1991), entre outros.

Para o psicólogo cognitivo e educacional, Howard Gardner (1999), é infundada a acusação de que a televisão é prejudicial e empobrece a criatividade e imaginação da criança em desenvolvimento. Segundo esse pesquisador, as mídias tecnológicas têm uma função primordial, que é a aceleração e afloramento da habilidade da criação, do imaginário, da representação social. Desde os primeiros anos de vida a criança é 
observadora, com um olhar perspicaz ao ambiente em que está inserida, conseguindo resolver os primeiros problemas que lhe surgem, mesmo que sua primeira opção seja chorar. Aos cinco ou seis anos já é suficientemente competente para relacionar-se e expressar suas vontades. Por isso, de acordo com Carlos A. Arnaldo ${ }^{12}$ (1999),

\begin{abstract}
Segundo a maioria dos estudos e pesquisas, as crianças não são nem espectadores, nem ouvintes, nem usuários passivos da mídia. A maioria dos estudos [...] enfatizou que as crianças têm uma abordagem ativa da mídia; elas abordam a mídia com sua "história pessoal", com "as construções sociais" que cultivaram na família, na comunidade e em seu ambiente jovem. [...] Por um lado, a mídia pode ser poderosa como fonte de informação, como influência potencial na formação das opiniões de jovens ou velhos, mas a mídia não é o determinante final ou único da formação das opiniões, do desenvolvimento de valores ou do comportamento sociocultural (ARNALDO, 1999, p. 448).
\end{abstract}

Lançando, então, um olhar comparativo entre a escola e a televisão, Magalhães (2003) observa que as duas têm alguns pontos em comum: "temos poucos transmitindo muitas informações (pensando informações como dados trabalhados) e para muitos; [...] os alunos/assistentes, em grande parte, colocados em um papel passivo diante do professor/TV". De qualquer forma, é possível afirmar que "a televisão educa os seus telespectadores. Só que, nem sempre, em benefício do próprio telespectador e da melhoria da sociedade em que vive" (MAGALHÃES, 2003, p. 41, 40).

Ainda segundo esse pesquisador, é preciso considerar que um mesmo telespectador tem diferentes olhares para os programas televisivos, e isso pode levá-lo a assistir ou não um determinado programa. "São olhares construídos socialmente, que dependem muito da subjetividade, da história pessoal de cada telespectador e de sua própria relação com a TV". Assim, a criança pode se interessar ou não por determinada programação, na medida em que ela faça sentido ou não para ela. "Mesmo parada em frente à televisão, a criança investe na sua relação com a TV, usando seu tempo e a si próprio como recursos" (MAGALHÃES, 2003, p. 43,44).

\title{
O ensino de música nas décadas de 1960, 1970 E 1980
}

Na década de 1960 estava em pleno funcionamento na escola pública brasileira, um movimento musical que fora iniciado por Heitor Villa-Lobos na década de 1930: o Canto Orfeônico. Os professores dessa disciplina deveriam "zelar pela execução correta

\footnotetext{
12 Chefe da Divisão de Comunicação da UNESCO, Paris.
} 
dos hinos oficiais e incentivar o gosto pelas demais canções de caráter cívico e artístico" (VILLA-LOBOS, 1991, p. 17).

O movimento desenvolvido por Villa-Lobos englobava não apenas a organização da prática musical nas escolas, mas também a formação e apresentação de grandes concentrações orfeônicas, a composição e arranjo de peças voltadas para o ensino dessa disciplina, além de um programa de formação de professores vinculado à SEMA (Superintendência de Educação Musical e Artística), criada em 1942 por Anísio Teixeira.

Nesse período outras ideias e tendências tiveram espaço e novos personagens começaram a ocupar o cenário do ensino musical. Um deles foi Antonio de Sá Pereira (1888-1966) que, em 1931 foi convidado para colaborar com a reforma curricular do Instituto Nacional de Música - posteriormente Escola Nacional de Música, quando de sua agregação à Universidade do Rio de Janeiro -, desenvolvendo a disciplina de Pedagogia Musical.

Outro nome importante foi o de Liddy Chiaffarelli Mignone (1891-1962), considerada uma das pioneiras na área de Iniciação Musical no Rio de Janeiro, levando esse curso também para o interior paulista. Ambos introduziram a disciplina de Educação Musical ${ }^{13}$ no Conservatório Brasileiro de Música em 1937, o qual havia sido fundado no Rio de Janeiro no ano anterior.

Em 1938, Sá Pereira inseriu esse curso na Escola Nacional de Música, que pertencia à Universidade do Brasil (antiga Universidade do Rio de Janeiro). Era inicialmente um curso de extensão, mas em 1946 foi adicionado ao currículo oficial. Essas classes, durante um bom tempo, serviram como treinamento para os alunos da graduação. Sá Pereira foi, também, diretor da Escola de Música até 1946 e foi seguido por Joanídia Sodré.

No cargo de diretora da Escola Nacional de Música, Joanídia Sodré criou o curso de formação de professores e a disciplina de Iniciação Musical, mesmo durante a vigência do Decreto 9.494 de 22 de julho de 1946, que regulamentava o ensino do Canto Orfeônico.

Em 22 de dezembro de 1960 foi promulgada a lei 3857, que criava a Ordem dos Músicos e regulamentava o exercício da profissão de músico. Uma das deliberações ali

\footnotetext{
${ }^{13}$ Essa disciplina enfatizava o uso de canções infantis e jogos musicais, levando os alunos primeiramente à prática, para depois aprenderem a leitura musical.
} 
presentes era que o exercício da profissão de músico seria livre, desde que exercido por pessoas diplomadas pela Escola Nacional de Música ou por estabelecimentos equivalentes (BRASIL, 1960, art. 28).

Havia, dessa forma, duas tendências vigentes na formação de professores, e certamente, no tipo e conteúdo de aulas ministradas: o Canto Orfeônico e a Iniciação Musical. Porém, em 1962, pelo Parecer 383 do Conselho Federal de Educação, os cursos superiores de música foram organizados em cinco anos letivos para instrumentistas, compositores e regentes e quatro anos para cantores e professores de Educação Musical. Note-se que a designação Canto Orfeônico não era mais utilizada.

Após o golpe militar de 1964, e com a crescente industrialização, um novo papel foi solicitado à educação: além de saber ler e escrever, era necessário criar ou educar pessoas para atuar no novo mercado de trabalho industrial. Nessa linha de pensamento, quem não tivesse formação técnica, seria considerado ineficiente e improdutivo.

Quanto ao ensino musical, pela Lei 5.692/71, passou a ser incluído no currículo escolar com o nome de Educação Artística, porém não como disciplina, mas como prática educativa, juntamente com outras atividades artísticas (artes visuais, teatro e desenho, substituído, mais tarde, pela dança). O discurso dos defensores da Educação Artística amparava-se no conceito modernista, que difundia a necessidade de ampliação do universo sonoro, da expressão musical comprometida com a prática, da livre experimentação, além da valorização do folclore e da música popular brasileira.

Assim, durante os anos 1970 e 1980, configurou-se a formação do professor polivalente em Arte. Os contrários viam nessa iniciativa a tendência à diminuição qualitativa dos saberes quanto às especificidades de cada uma dessas modalidades artísticas, ou seja, o professor não teria condições de dominar as técnicas inerentes a cada uma delas.

Qual seria, então, o papel atribuído à música? Segundo o Parecer 540/77, do Conselho Federal de Educação, que comentava sobre o tratamento a ser dado aos componentes curriculares estabelecidos como obrigatórios no artigo $7^{\mathrm{o}}$ da Lei 5.692 (Educação Moral e Cívica, Educação Física, Educação Artística e Programas de Saúde), antes da lei 5.692, embora a música fosse tratada como disciplina, não dava margem à criatividade e autoexpressão dos alunos, nem mesmo nas atividades de canto coral (BRASIL, 1977, p. 26-28). 
Ainda segundo esse documento, o principal objetivo da Educação Artística seria deter-se "no aguçamento da sensibilidade que instrumentaliza para a apreciação, no desenvolvimento da imaginação, em ensinar a sentir, em ensinar a ver como se ensina a ler, [...] o que tem a ver diretamente com o lazer" (BRASIL, 1977, p. 26).

Essa questão gerou muitas polêmicas. O sociólogo francês Jofre Dumazedier (1915-2002) esteve várias vezes no Brasil, proferindo palestras a convite do Serviço Social do Comércio (SESC) em São Paulo, da Universidade de Brasília e de líderes de movimentos religiosos em Pernambuco, influenciando assim outros pesquisadores. Segundo esse pesquisador,

O lazer é um conjunto de ocupações às quais o indivíduo pode entregar-se de livre vontade, seja para repousar, seja para divertir-se, recrear-se e entreter-se ou ainda, para desenvolver sua informação ou formação desinteressada, sua participação social voluntária ou sua livre capacidade criadora após livrar-se ou desembaraçar-se das obrigações profissionais, familiares e sociais (DUMAZEDIER, 2004, p.34).

Para o sociólogo francês, o lazer pode desempenhar três funções: a função de descanso, a função de divertimento, recreação e entretenimento e a função de desenvolvimento. $\mathrm{Na}$ função de descanso, o lazer é visto como um "reparador das deteriorações físicas e nervosas provocadas pelas tensões resultantes das obrigações cotidianas e, particularmente, do trabalho". Na função de divertimento, recreação e entretenimento o lazer seria uma resposta à "necessidade de ruptura com o universo cotidiano" desde que proporcione "complementação, compensação e fuga das disciplinas e coerções necessárias à vida social”. Finalmente, a função do lazer enquanto desenvolvimento da personalidade se dá através de atividades que estimulem a participação social, possibilitando "o desenvolvimento livre de atitudes adquiridas na escola, sempre ultrapassadas pela contínua e complexa evolução da sociedade", chegando até as formas de "aprendizagem voluntária" (DUMAZEDIER, 2004, p. 32$34)$.

O sociólogo Nelson Carvalho Marcellino (2001), estudando sobre as características do lazer e sua relação com a educação aponta que podem ser encontradas duas tendências: o lazer como "atitude", que considera o lazer como estilo de vida, independente de uma ocasião ou um tempo determinado. Segundo ele, "o lazer considerado como "atitude" será caracterizado pelo tipo de relação verificada entre o sujeito e a experiência vivida, basicamente, a satisfação provocada pela atividade". 
Além disso, há os que associam o lazer a um tempo específico, onde não se faça nenhum trabalho, ou seja, o tempo livre (MARCELLINO, 2001, p. 29).

Assim, as aulas de Educação Artística, segundo esse documento, deveriam proporcionar aos alunos certo descanso ou refrigério em relação às demais atividades. Dessa forma, o professor de Educação Artística e, mais especificamente de música, deveria proporcionar aos alunos a oportunidade de realizar atividades criadoras, pois elas "compensam os sentimentos de insatisfação derivados da divisão do trabalho e da sua mecanização". Por isso, "os que detêm alguma parcela de responsabilidade no bemestar público já descobriram no lazer poderoso recurso de ajustamento dos homens" (MEDEIROS, 1971, p. 104, 105).

Pode-se, então pensar no conceito de lazer como algo que, de alguma forma, trouxesse condições favoráveis ao processo educativo e produtivo.

\section{Ensino de música, televisão e lazer}

Os documentos que norteavam o ensino de música nas décadas de 1970 e 1980, especialmente o Parecer 540/77 ressaltavam a importância do desenvolvimento da criatividade e da autoexpressão dos alunos. As publicações, entretanto, não continham orientações claras sobre a melhor forma de se trabalhar esses aspectos e nem de como lidar com as atividades de diversas áreas de maneira harmonizada. Essas novas capacidades também não eram contempladas nos cursos de licenciatura.

Examinando as publicações da época, pode-se verificar o que se entendia por criatividade. Em seu livro, “Arte e ciência da criatividade”, George Kneller (1973) ${ }^{14}$ afirma que as definições existentes para criatividade pertencem a quatro categorias:

[...] ela pode ser considerada do ponto de vista da pessoa que cria, isto é, em termos de fisiologia e temperamento, inclusive atitudes pessoais, hábitos e valores. Pode também ser explanada por meio de processos mentais motivação, percepção, aprendizado, pensamento e comunicação - que o ato de criar mobiliza. Uma terceira definição focaliza influências ambientais e culturais. Finalmente, a criatividade pode ser entendida em função de seus produtos, como teorias, invenções, pinturas, esculturas e poemas (KNELLER, 1973, p.15).

Explicações como essa deixavam espaço para se compreender criatividade de várias maneiras, e talvez não despertassem a curiosidade e o pensamento reflexivo do

\footnotetext{
${ }^{14}$ Professor de Filosofia da Educação da University of California, Los Angeles (UCLA).
} 
professor. Eunice Maria Lima Soriano de Alencar ${ }^{15}$ (1974), nesse mesmo período, considerava que a criatividade havia sido abordada de diversos modos. Para ela, algumas teorias enfatizavam mais os aspectos motivacionais e de personalidade da pessoa criativa, enquanto outras se detinham nos aspectos intelectuais e cognitivos. Na primeira linha de estudos, entendia-se que a criatividade contemplava três condições básicas: 1) dava uma resposta nova ou incomum a uma situação; 2) essa resposta deveria se adaptar à realidade, contribuindo para o alcance de um objetivo reconhecível; 3) deveria incluir uma avaliação. A autora chamava a atenção para que se considerasse não somente a existência da criatividade artística, mas também da científica. Na segunda linha levavam-se em conta os diversos tipos de operações intelectuais. Uma delas seria o "pensamento divergente", que se refere às "habilidades de gerar variedades de informações a partir de uma dada informação e engloba diferentes fatores como fluência, flexibilidade e elaboração" (ALENCAR, 1974, p. 61).

Ainda nessa linha de pensamento, segundo essa pesquisadora, a criatividade também podia ser entendida como "o processo de se tornar sensitivo a problemas, deficiências, lacunas no conhecimento; identificar a dificuldade; buscar por soluções, formulando hipóteses a respeito das deficiências; testar e retestar as hipóteses, possivelmente modificando-as, e finalmente comunicando os resultados" (ALENCAR, 1974, p. 62).

Sob essa ótica, não seria possível que os programas televisivos educativos contribuíssem para o desenvolvimento de seus telespectadores? Gardner (1999) considera que crianças com déficit de atenção podem ser auxiliadas por programas que se utilizem largamente dos zooms, pois "o meio pode suplantar uma habilidade que a criança precisa, mas que, por uma razão ou outra, ela ainda não desenvolveu por conta própria". E mais adiante, afirma que "o indivíduo que vê televisão intensiva e extensivamente pode muito bem desenvolver tipos diferentes de poderes imaginativos" (GARDNER, 1999, p. 203, 205).

Segundo esse pesquisador, a criança passa por determinadas fases no processo de assistir e entender o que é transmitido pela televisão. Dessa forma,

Para a criança de um ou dois anos, a televisão apresenta um exército de imagens isoladas que não guardam qualquer conexão entre si. [...] Aos três ou quatro anos, a criança começa a perceber que a televisão apresenta narrativas que podem ser interrompidas de tempos em tempos por comerciais. [...] Aos

15 Professora emérita da Universidade de Brasília. 
cinco anos [...] a criança regularmente aponta tanto as semelhanças como as diferenças entre o mundo televisivo e o mundo real (GARDNER, 1999, p. 208, 209,210).

Seguindo costumeiramente a programação, as crianças aos três ou quatro anos adquirem um senso de horário de seus programas favoritos e "reconhecem que quando um personagem desaparece com o fim do show ele não vai voltar até amanhã" (GARDNER, 1999, p. 211).

\begin{abstract}
De modo geral, então, estudos de crianças assistindo à televisão apoiam a visão geral da criança como um solucionador de problemas inteligente e ativo. [...] Minhas observações, bem como as de outros pesquisadores, documentam que a televisão pode abastecer a imaginação da criança. Em anos passados a imaginação das crianças era estimulada pelos eventos e personagens que a elas eram narrados; ou, em tempos um pouco mais recentes, pelas figuras e histórias que elas encontravam em forma de livro. Agora, no entanto, essas fontes foram, em grande parte, suplantadas pelos personagens e por eventos que os jovens encontram na televisão (GARDNER, 1999, p. 216).
\end{abstract}

Considerando que os programas infantis, desenhos animados e comerciais se utilizam da música em larga escala podemos observar que a criança ouve música enquanto assiste essas programações e pode reconhecer o início ou o fim do seu programa favorito, ou a anúncio de determinados produtos pelos jingles utilizados.

Dessa forma, os programas televisivos podem vir a contribuir como base para novas descobertas de escutas musicais, partindo da convicção de que a consciência estética das pessoas é construída ao longo de suas vivências, de seus modos de valoração.

No período estudado, entretanto, observou-se uma nítida diminuição da presença da música em sala de aula como conteúdo de ensino, ocupando um lugar importante apenas nas festas e comemorações.

As mudanças percebidas no perfil dos alunos a partir da década de 1960 com o advento da televisão - que trouxe programas de entretenimento e também alguns considerados educativos e direcionados ao público infantil - acarretaram uma alteração muito significativa no comportamento e também no gosto musical das crianças e adolescentes, o que certamente exigiu do professor, mais uma vez, uma nova prática docente sem suporte teórico e prático. 
Mariangela Momo e Marisa Vorraber Costa ${ }^{16}$, estudando o comportamento escolar de crianças em escolas de periferia na atualidade, observaram que até o século XIX os pequenos apresentavam-se mais "ingênuos, dóceis e dependentes dos adultos" (MOMO e COSTA, 2010, p. 967-8). Na época presente, entretanto, dentre os alunos observados foram encontrados alguns que procuram de modo incansável,

[...] se inscrever na cultura globalmente reconhecida e fazer parte de uma comunidade de consumidores de artefatos em voga na mídia do momento; que produzem seu corpo de forma a harmonizá-lo com o mundo das imagens e do espetáculo; que se caracterizam por constantes e ininterruptos movimentos e mutações. São crianças que buscam infatigavelmente a fruição e o prazer e, nessa busca, borram fronteiras de classe, gênero e geração (MOMO e COSTA, 2010, p. 969).

Pode-se perceber que o consumismo se transformou não apenas no eixo organizador das sociedades capitalistas da atualidade, mas também na norma de conduta de crianças e adolescentes. Assim, as "identidades e as subjetividades dos infantis são forjadas em um cenário pós-moderno - do consumo, do espetáculo, das visibilidades, da efemeridade, da mídia, das tecnologias, dentre outras dimensões". Nesse contexto, o que determina a permanência ou descarte dos objetos associados aos ícones midiáticos "são os significados a eles relacionados, aquilo que faz deles não simples objetos, mas artefatos culturais". Por isso, o "estado de televisão, que as crianças experimentam, inclui, além da ausência de silêncio e da ininterrupta movimentação, falar constantemente de programas televisivos, cantar e dançar os últimos lançamentos de músicas e atuar com brinquedos amplamente divulgados pela mídia" (MOMO e COSTA, 2010, p. 971-3).

Hoje a televisão é um veículo que atrai pessoas de todas as idades, combinando a audição e visão, mas também instigando o olfato pelos efeitos da imagem em movimento. "Desde a mais tenra idade as crianças ouvem e reproduzem as canções de sucesso, especialmente aquelas veiculadas nas novelas, nos programas de auditório, nos comerciais e nos programas de rádio, substituindo as tradicionais canções infantis" (SUBTIL, 2007, p. 75).

Além disso, a televisão cativa os indivíduos não letrados, crianças em idade préescolar, jovens e adultos que não frequentaram a escola, mas também aqueles com maior grau de escolaridade. Por isso, é urgente contextualizar as aulas de música, pois

\footnotetext{
${ }^{16}$ Professoras respectivamente do Departamento de Educação da Universidade Federal do Rio Grande do Norte e da Pós-graduação em Educação da Universidade Federal do Rio Grande do Sul e da Universidade Luterana do Brasil.
} 
Enquanto isso não ocorrer, os alunos continuarão distinguindo aula de música de música propriamente dita. Em outras palavras, eles continuarão entendendo que música é o que eles ouvem em casa, pelo rádio, TV e internet, enquanto a aula de música não trata de música necessariamente (SOUZA, 2013, p. 61).

Desse modo, a escola pode e deve desenvolver um papel mediador que pode favorecer a produção de conhecimentos sobre a música na explicitação da cultura midiática em sua dimensão histórica e social possível.

\section{Considerações finais}

Vimos que é importante saber utilizar o que a criança traz consigo, principalmente em termos de repertório musical, promover reflexões sobre a necessidade do acesso às obras primas musicais tanto modernas quanto as já consagradas historicamente pela humanidade, cuidadosamente entrelaçadas aos saberes musicais presentes no cotidiano do aluno.

Outro aspecto de suma importância é que, sendo veiculada pela TV inclusive nos programas infantis, a música tem se configurado como um meio de comunicação predominante, além de ser instrumento de socialização, entretenimento, informação, publicidade, desempenhando um papel educacional relevante, uma vez que nossas crianças passam mais tempo diante do televisor do que na escola ou em outra atividade.

Como refere Barroso (2004), uma abordagem política e sociológica da escola não pode ignorar a sua dimensão cultural, quer numa perspectiva global, no quadro da relação que ela estabelece com a sociedade em geral, quer numa dimensão mais específica, em função das próprias formas culturais que ela produz e transmite.

Com base nessa visão podemos constatar, como afirma Queiroz (2003, p. 3) "que a educação poderia e deveria ser o principal e mais importante caminho para estimular a consciência cultural do indivíduo, começando pelo reconhecimento e a apreciação da 'cultura local', pois reconhecer sua própria cultura é conhecer a si próprio".

A fruição da música está sujeita a diferentes mediações e a escola pode vir a ser o lugar de construção de um conhecimento significativo e de formação humanizadora. Por isso, é preciso refletir sobre o uso que é feito pela escola das músicas veiculadas pela mídia, especialmente nas programações destinadas ao público infantil, pois "além de ser uma ferramenta pedagógica valiosa, a televisão é uma outra "linguagem", um 
outro meio de expressão, que os jovens estudantes, como telespectadores, deveriam aprender a "ler" criticamente. (ARNALDO, 1999, p.442)

Dessa forma, a grande questão a ser refletida não se prende ao fato de consumir ou não as músicas veiculadas pela mídia, "mas em não remodelá-las com novo significado, de acordo com suas particularidades. Em outras palavras, é se apropriar delas, não apenas como informação, mas como conhecimento significativo" (SOUZA, 2013, p. 58).

Se uma escola não ensina a assistir à televisão ou ainda apreciar uma boa música seja qual for seu estilo cultural, para que mundo está educando? Se educar exige a preparação reflexiva e crítica na sociedade, como as crianças poderão refletir de forma crítica sobre aquela atividade à qual dedicam a maior parte do seu tempo?

$\mathrm{O}$ professor enquanto mediador entre os bens culturais e o aluno, precisa também ter amplo acesso às várias formas de expressão da cultura, para poder trabalhar com elas em sala de aula. Se tais atividades integrarem a vida docente, esta mediação necessária entre as manifestações culturais e o aluno será mais facilmente realizada.

\section{Referências}

ALENCAR, Eunice Maria Soriano de Alencar. Um estudo de criatividade. Arquivo Brasileiro de Psicologia Aplicada. Rio de Janeiro, 26(2), abr./jun.1974, p. 59-68. Disponível em http://bibliotecadigital.fgv.br/ojs/index.php/abpa/article/viewFile/17077/15876. Acesso: 21 ago. 2016.

ARIÈS, Philippe. História social da criança e da família. 2. Ed. Rio de Janeiro: Guanabara, 1973.

ARNALDO, Carlos A. Meios de comunicação: a favor ou contra a educação? In: CARLSSON, Ulla; FEILITZEN, Cecilia von (orgs.). A criança e a mídia. Imagem, Educação, Participação. São Paulo: Cortez; Edições UNESCO Brasil, 1999. Disponível em ht0tp://unesdoc.unesco.org/images/0012/001278/127896por.pdf. Acesso: 30 ago. 2017.

BARROSO, João. Políticas educativas e organização escolar. Lisboa: Universidade Aberta, 2004.

BERGAMO, Alexandre. A reconfiguração do público. In: GOULART, Ana Paula; RIBEIRO, Igor Sacramento e ROXO, Marco (orgs.). História da televisão no Brasil. São Paulo: Contexto, 2010. 
BIASOLI-ALVES, Zélia Maria Mendes. Famílias brasileiras do século XX: os valores e as práticas de educação da criança. Temas em Psicologia, Ribeirão Preto, SP, n. 3, 1997, p. 33-49.

BRASIL. Lei 3.857 de 22 de dezembro de 1960. Cria a Ordem dos Músicos do Brasil e Dispõe sobre a Regulamentação do Exercício da Profissão de Músico e dá outras Providências. Disponível em http://www.planalto.gov.br/ccivil_03/LEIS/L3857.htm. Acesso: 03 de nov. 2015.

Parecer $n^{\circ}$ 540/77, de 10 de fevereiro de 1977, do CFE. Sobre o tratamento a ser dado aos componentes curriculares previstos no Art. $7^{\circ}$ da Lei 5692/71. In Documenta $\mathrm{n}^{\circ}$ 195, p. 22-34. Rio de Janeiro, fev. 1977. Disponível em http://www.histedbr.fae.unicamp.br/navegando/fontes_escritas/7_Gov_Militar/parecer \%20n.\%205401977\%20sobre\%20o\%20tratamento\%20a\%20ser\%20dado\%20aos\%20co mp\%20curriculares.pdf. Acesso: 26 jul. 2014.

BUJES, Maria Isabel Edelweiss. Manuais pedagógicos e formação docente: elos de poder/saber. Currículo sem Fronteiras, v.9, n.1, p.267-288, Jan/Jun 2009. Disponível em http://www.curriculosemfronteiras.org/vol9iss1articles/bujes.pdf. Acesso: 4 set. 2016.

CARMONA, Beth. A participação da criança na televisão brasileira. In: CARLSSON, Ulla; FEILITZEN, Cecilia von (orgs.). A criança e a mídia. Imagem, Educação, Participação. São Paulo: Cortez; Edições UNESCO Brasil, 1999. Disponível em ht0tp://unesdoc.unesco.org/images/0012/001278/127896por.pdf. Acesso: 30 ago. 2017.

CHERVEL, A. História das disciplinas escolares: reflexões sobre um campo de pesquisa. Teoria e Educação. Porto Alegre, no 2, p. 177-229, 1990. Disponível em <http://pt.scribd.com/doc/88143953/CHERVEL-1990-Original>. Acesso: 11 jun.2012.

COGO, Denise Maria; GOMES, Pedro Gilberto. Televisão, escola e juventude. Porto Alegre: Mediação, 2001.

DUMAZEDIER, Jofre. Lazer e cultura popular. 3. Ed. São Paulo: Perspectiva, 2004.

FIGUEIREDO, Anna Cristina Camargo Moraes. Liberdade é uma calça velha azul e desbotada: publicidade, cultura de consumo e comportamento político no Brasil (19541964). São Paulo: Hucitec, 1998.

FISCHER, Rosa Maria Bueno. Televisão e Educação: fruir e pensar a TV. 4. Ed. Belo Horizonte: Autêntica Editora, 2013.

GARDNER, Howard. Arte, mente e cérebro. Tradução. Sandra Costa. Porto Alegre: Artes Médicas Sul, 1999. Original em inglês. 
GOMES, N. L. Cultura negra e educação. Revista Brasileira de Educação, $n^{\circ}$ 23, Mai/Jun/Jul/Ago. 2003.

HAMBURGUER, Esther. Diluindo fronteiras: a televisão e as novelas no cotidiano. In: NOVAIS, Fernando A. (Coord.). História da vida privada no Brasil: contrastes da intimidade contemporânea. São Paulo: Companhia das Letras, 2000, v. 4.

JULIA, Dominique. A cultura escolar como objeto histórico. Tradução. Gizele de Souza. In Revista Brasileira de Educação, nº 1 jan/jun. 2001. Campinas, SP: Editora Autores Associados, 2001, p. 9-43.

KEHL, Maria Rita. Eu vi um Brasil na TV. In: CARVALHO, Elisabeth; KEHL, Maria Rita; RIBEIRO, Santuza Naves. (Coord.). Anos 70: televisão. Rio de Janeiro: Europa, 1980.

KNELLER, George F. Arte e Ciência da Criatividade. Tradução. José Reis. 3. Ed. São Paulo: IBRASA - Instituição Brasileira de Difusão Cultural S.A., 1973. Original em inglês.

MAGALHÃES, Cláudio Márcio. A inter-relação entre criança e TV. Comunicação \& Educação, São Paulo, 27, maio/ago, 2003, p. 38-45.

Os programas infantis da TV: Teoria e Prática para entender a televisão feita para as crianças. $1^{\mathrm{a}}$ ed. São Paulo: Autêntica, 2007.

MARCELLINO, Nelson Carvalho. Lazer e educação. $8^{\text {a }}$ Ed. Campinas, SP: Papirus, 2001.

MATTOS, Sérgio. História da televisão brasileira: uma visão econômica, social e política. 2. ed. Petrópolis: Vozes, 2002.

MEDEIROS, Ethel Bauzer. O lazer no planejamento urbano. Cadernos de Administração Pública - 82. Fundação Getúlio Vargas, Instituto de Documentação Serviço de Publicações. Rio de Janeiro, GB, Brasil, 1971.

MOMO, Mariangela; COSTA, Marisa Vorraber. Crianças escolares do século XXI: para se pensar uma infância pós-moderna. Cadernos de Pesquisa, v.40, n.141, p.965991, set./dez. 2010.

NASCIMENTO, Cláudia Terra do; BRANCHER, Vantoir Roberto; OLIVEIRA, Valeska Fortes de. A construção social do conceito de infância: algumas interlocuções históricas e sociológicas. Contexto \& Educação, Editora Unijuí, v. 23, n. 79, jan./jun., 2008, p.47-63.

PACHECO, Elza D. (org.). Televisão, criança, imaginário e educação. Campinas, SP: Papirus, 1998. 
PENTEADO, Heloísa D. Televisão e escola - conflito ou cooperação. São Paulo: Cortez, 1991.

PILLAR, Analice Dutra. Criança e televisão. Porto Alegre: Mediação, 2001.

QUEIROZ, Luis Ricardo S. Educação musical e etnomusicologia: uma reflexão sobre as contribuições do estudo etnomusicológico para a área de educação musical. In:

Congresso da Associação Nacional de Pesquisa e pós-graduação em música, 14., 2003, Porto Alegre. Anais... Porto Alegre: ANPPOM, 2003. p. 772-779. 1 CD-ROM.

SOUZA, Cristiane Magda Nogueira. Educação musical, cultura e identidade: configurações possíveis entre escola, família e mídia. Revista da ABEM, Londrina, V.21, N.31, jul/dez, 2013, p. 51-62.Disponível em http://www.abemeducacaomusical.com.br/revistas/revistaabem/index.php/revistaabem/a rticle/view/72. Acesso: 30 jul. 2017.

STEINBERG, Shirley; KINCHELOE, Joe. Cultura infantil: a construção corporativa da infância. Editora Civilização Brasileira, 2001.

SUBTIL, Maria José Dozza. Mídias, músicas e escola: a articulação necessária. Revista da ABEM, Porto Alegre, V. 16, 75-82, mar.2007. Disponível em http://www.abemeducacaomusical.com.br/revistas/revistaabem/index.php/revistaabem/a rticle/view/294. Acesso: 10 ago. 2017.

TEIXEIRA, Luiz M. A criança e a televisão: amigos ou inimigos? 2.Ed. São Paulo: Editora Loyola, s.d.

TEMPO DE CRIANÇAS E ADOLESCENTES ASSISTINDO TV AUMENTA EM 10 ANOS, 2015. Disponível em http://www.ebc.com.br/infantil/para-pais/2015/06/tempode-criancas-e-adolescentes-assistindo-tv-aumenta-em-10-anos. Acesso: 05 ago. 2017.

VASCONCELOS, Gilberto F. O cabaré das crianças. Rio de Janeiro: Espaço \& Tempo, 1998.

VILLA LOBOS, Heitor. Educação Musical. Rio de Janeiro: Museu Villa-Lobos, 1991. Reedição com ortografia atualizada do texto Educação Musical de H. Villa-Lobos publicado pelo Instituto Interamericano de Musicologia no Boletim Latino-Americano de Música, Ano VI, Tomo VI - Rio de Janeiro, 1946.

VIÑAO FRAGO, Antonio. Historia de la educación y historia cultural: Posibilidades, problemas, cuestiones. Revista Brasileira de Educação, Set/Out/Nov/Dez, 1995 N $^{\circ} 0$, p. $63-82$ 